\title{
Gender Related Modification in ECG and VCG in Elderly People
}

\author{
Giovanni Bortolan ${ }^{1}$, Ivaylo Christov ${ }^{2}$, Iana Simova ${ }^{3}$ \\ ${ }^{1}$ Institute of Neuroscience IN-CNR, Padova, Italy \\ ${ }^{2}$ Institute of Biophysics and Biomedical Engineering, Bulgarian Academy of Sciences, Sofia, Bulgaria \\ ${ }^{3}$ Heart and Brain Center of Excellence, University Hospital, Pleven, Bulgaria
}

\begin{abstract}
Objective: Objective of the current study is to investigate the effect of cardiovascular diseases and diabetes mellitus on modifications in electrocardiographic (ECG) and vectorcardiographic (VCG) features, considering an elderly population, most of them with multiple comorbidities.

Materials. Italian Longitudinal Study on Aging (ILSACNR) database was created to evaluate physiologic and pathologic modifications connected with aging. Standard 12-leads ECG recordings (10 sec, $500 \mathrm{~Hz})$ were taken with a follow-up of three years. The study examined 1109 males and 918 females aged 65-84 years. All considered parameters were 21: 10 from ECG signal, 10 from VCG signal and Heart Rate (HR).

Results and Discussion. Groups with different heart diseases (Diabetes, Angina, Hypertension, Myocardial Infarction and Arrhythmia) are compared to the Healthy group. Only five parameters (T-wave area dispersion, $T$ ratio, T-roundness, T-PCA and T amplitude) all related to $T$-wave, presented statistically significant differences both for males and females between Healthy and heart diseases group. For QRS related parameters there is different behavior between males and females. Myocardial Infarction, Arrhythmia, and Heart Failure are the diseases with greatest impact on the ECG and VCG parameters.
\end{abstract}

\section{Introduction}

Electrocardiographic (ECG) and vectorcardiographic (VCG) morphological abnormalities have been used for long in detection of cardiovascular diseases and prediction of the risk for sudden cardiac death. Some parameters as ST-segment elevation, QRS-complex duration, QT dispersion, T-wave area dispersion, spatial QRS-T angle, etc. have established clinical significance.

For example, measurements and analysis of STelevation were studied as a risk factor in different groups of hemodialysis patients $[1,2]$.
A prolonged QRS duration was an independent predictor of increased total mortality or sudden death [3, 4].

QT interval dispersion (QTd) reflects the inhomogeneity of electrical activity in different segments of left ventricle, and several studies showed an increase of QT dispersion in various cardiac diseases $[5,6]$.

In addition, normal aging is associated with several functional and structural changes in the cardiovascular system, and heart aging is manifested in increased heart's mass and fibrosis of the conduction system. [7, 8], and in elderly people, the occurrence of widespread histologic changes in the conduction system may alter several features of the electrocardiogram.

In a previous study [7] serial ECG recordings in elderly people were examined and an age-related ECG attenuation (QRS- and T-waves) was found in males, but not in females. This finding was not associated with any specific cardiovascular disease, and was also present in the healthy subgroup.

Objective of the current study is to investigate genderrelated effects of cardiovascular diseases and diabetes mellitus on modifications in ECG and VCG features, considering an elderly population. The population based sample examined was characterized by multiple comorbidities.

\section{Materials}

This study considers a subset of an ECG database developed in the framework of Italian Longitudinal Study on Aging project (ILSA-CNR). This database was created to evaluate physiologic and pathologic modifications connected with aging [9].

Standard 12-leads ECG recordings $(10 \mathrm{sec}, 500 \mathrm{~Hz})$ were taken at baseline and after three years. The database consisted of a random sample of individuals aged 65-84 years, living independently or in institutions, stratified by age and sex using the equal allocation strategy, identified on the demographic list of the registry office of eight Italian municipalities. 
Table 1 Distribution of the male population $(n=1109)$ in the groups of: Healthy, Diabetes Mellitus, Angina Pectoris, Hypertension, Myocardial Infarction, Arrhythmia, Congestive Heart Failure.

\begin{tabular}{lccccccc}
\hline \hline & Healty & Diab.M & AnginaP. & Hypert & Myoc.Inf & Arrhyt & C.Hrt.Flr \\
\cline { 2 - 8 } Healty & $\mathbf{2 1 9}$ & 0 & 0 & 0 & 0 & 0 & 0 \\
Diab.M & 0 & $\mathbf{1 3 0}$ & 14 & 96 & 28 & 57 & 10 \\
Angina P. & 0 & 14 & $\mathbf{9 9}$ & 69 & 41 & 41 & 15 \\
Hypert & 0 & 96 & 69 & $\mathbf{6 0 7}$ & 99 & 252 & 50 \\
Myoc.Inf & 0 & 28 & 41 & 99 & $\mathbf{1 6 0}$ & 72 & 28 \\
Arrhyt & 0 & 57 & 41 & 252 & 72 & $\mathbf{3 8 6}$ & 47 \\
C.Hrt.Flr & 0 & 10 & 15 & 50 & 28 & 47 & $\mathbf{7 3}$ \\
\hline \hline
\end{tabular}

Table 2. Distribution of the female population $(n=918)$ in the groups of: Healthy, Diabetes Mellitus, Angina Pectoris, Hypertension, Myocardial Infarction, Arrhythmia, Congestive Heart Failure

\begin{tabular}{lccccccc}
\hline \hline & Healty & Diab.M & Angina P. & Hypert & Myoc.Inf & Arrhyt & C.Hrt.Flr \\
\cline { 2 - 8 } Healty & $\mathbf{1 6 1}$ & 0 & 0 & 0 & 0 & 0 & 0 \\
Diab.M & 0 & $\mathbf{1 3 6}$ & 18 & 117 & 14 & 51 & 28 \\
Angina P. & 0 & 18 & $\mathbf{7 9}$ & 67 & 18 & 36 & 16 \\
Hypert & 0 & 117 & 67 & $\mathbf{6 4 8}$ & 49 & 194 & 75 \\
Myoc.Inf & 0 & 14 & 18 & 49 & $\mathbf{6 6}$ & 22 & 16 \\
Arrhyt & 0 & 51 & 36 & 194 & 22 & $\mathbf{2 6 2}$ & 47 \\
C.Hrt.Flr & 0 & 28 & 16 & 75 & 16 & 47 & $\mathbf{9 5}$ \\
\hline \hline
\end{tabular}

The following diagnostic groups have been considered for the analysis:

- Patients with a history of cardiovascular disease: arrhythmia (ARRH), angina pectoris (AP), myocardial infarction (MI), congestive heart failure (CHF), hypertension (HYPT).

- Patients with diabetes mellitus DM

- Healthy subjects, characterized by the absence of any cardiovascular, neurological, chronic pulmonary disease or diabetes, by the absence of therapy potentially influencing cardiac electrical activity, and by the absence of electrolyte imbalance.

A group of 1109 males and 918 females was involved in the study, and their composition are reported in Table 1 (Male) and Table 2 (Female).

\section{Methods}

The ECG signals were preprocessed to eliminate or suppress the powerline interference [11], the drift of the baseline [12] and the electromyographic noise [13].

For this study, 21 parameters were considered: 10 from ECG signal, 10 from VCG and the Heart Rate (HR). All ECG/VCG parameters were automatically measured, assuring the repeatability of the results.

The ten considered ECG parameters are the following: QRS-amplitude, QRS-PCA, QRS duration, QT-interval duration, T duration, QT-dispersion, ST-elevation, Tamplitude, T-PCA, T-area dispersion.

For example, the QRS-PCA and T-PCA are morphology parameters based on all 12 ECG leads. They are computed by Principle Component Analysis (PCA) through singular value decomposition, applied to QRS and $\mathrm{T}$-wave intervals of all leads. They are defined as the ratio between the second and the first Eigen values (complexity index):

$$
\text { QRS_PCA: } \lambda_{2(\mathrm{QRS})} / \lambda_{1(\mathrm{QRS})}
$$$$
\text { T PCA: } \lambda_{2(\mathrm{~T})} / \lambda_{1(\mathrm{~T})}
$$

The T-area dispersion TWAD [14], was calculated as the average of normalized T-wave areas in specific standard leads, and it is defined by:

$$
\begin{gathered}
T W A D=\frac{1}{N} \sum_{i=1}^{N} \frac{\text { Area }_{i}}{\max \left(\mid \text { Area }_{i: N} \mid\right)}, \\
i \in\left\{I, I I, V_{4}, V_{5}, V_{6}\right\}
\end{gathered}
$$

TWAD was calculated from leads $\{$ I, II, V4, V5, V6 \}, because $\mathrm{T}$ waves in these leads were normally positive, and inversions in them conveyed prognostic value.

The 10 VCG parameters were the following: QRSarea, maximal QRS vector, QRS-angle, QRS-roundness index, T-area, maximal T-vector, T-angle, QRS/T-angle, $\mathrm{T}$-vector ratio, and T- roundness index. Orthogonal Frank $\mathrm{X}, \mathrm{Y}$ and $\mathrm{Z}$ leads were derived from the standard 12-leads, using the transfer matrix of Dower, 1968 [15]. Several vectorcardiographic 3-D and frontal plane 2-D parameters were measured such as: maximal vector of QRS- and Tloops, area of the loops, angles of the maximal vectors.

Another parameter, characterizing the roundness (circularity) of the loop, was the roundness index (RI) for QRS and T waves, measured as the ratio of the area of the QRS or $\mathrm{T}$ loop to the square of the corresponding 
maximum vector [16]:

QRS_RI $=$ QRS_Area $/ \operatorname{Vmax}^{2}$

$\mathrm{T}$ RI $=\mathrm{T}$ Area/Vmax ${ }^{2}$

The $\overline{\mathrm{T}}$-loop vector ratio $\left(\mathrm{VR}_{\mathrm{T}}\right)$ is defined by

$\mathrm{VR}_{\mathrm{T}}=\max \left(\mathrm{V}_{\mathrm{n}}\right) / \operatorname{mean}\left(\mathrm{V}_{\mathrm{n}}\right)$ for $\{\mathrm{n}\}$ in $\mathrm{T}$ loop

where $\mathrm{Vn}$ is given by:

$$
V_{n}=\sqrt{X_{n}^{2}+Y_{n}^{2}+Z_{n}^{2}}
$$

The parameters of the considered groups were described by descriptive statistics (mean and standard deviation) and by the limits of the $95 \%$ confidence interval. Nonparametric

Wilcoxon rank sum test (for equality of population medians) was used for testing the statistical significance of the comparisons between healthy vs groups with cardiac diseases and diabetics. All statistical analysis and data visualization were performed with Matlab R2019b.

\section{Results and Discussion}

All the electrocardiographic features were analysed considering the 7 diagnostic groups of the ILSA Database. A statistical analysis of the considered parameters was performed for all the 7 diagnostic groups. The mean values, the standard deviation and the $95 \%$ confidence interval were analyzed and studied, and Table 3 reports an example for the male population considering the QRS and $\mathrm{T}$ wave amplitudes in the Healthy, DM, HYPT and MI groups, while the same parameters and diagnostic groups are reported in Table 4 for the Female population. Comparison between the healthy group and all the other diagnostic groups was performed in order to test and to quantify their influence on the ECG and VCG parameters.

In particular, the ECG and VCG parameters of the healthy control group $(\mathrm{n}=219 \mathrm{M}, 161 \mathrm{~F})$ were compared with respect to the other groups: Diabetics DM ( $n=130 \mathrm{M}$, 136F), Angina Pectoris AP ( $\mathrm{n}=99 \mathrm{M}, 79 \mathrm{~F})$, Hypertension HYPT $(\mathrm{n}=607 \mathrm{M}, 648 \mathrm{~F})$, Myocardial Infarction MI $(\mathrm{n}=160 \mathrm{M}, 66 \mathrm{~F})$, Arrhythmia ARRH $(\mathrm{n}=386 \mathrm{M}, 262 \mathrm{~F})$, Congestive Heart Failure CHF $(n=73 \mathrm{M}, 95 \mathrm{~F})$. Comorbid patients with different cardiovascular diseases (see Table 1 and Table 2) were examined more than ones in the corresponding groups.

Table 5, Table 6 and Table 7 reports the comparison of the Healthy group with respect to DM, AP, HYPT, MI ARRH and CHF considering different parameters for male and Females.

Only five parameters (T-wave area dispersion, T-ratio, T-roundness, T-PCA and $\mathrm{T}$ amplitude) all related to $\mathrm{T}$ wave, presented statistically significant differences both for males and females between Healthy and heart diseases group. For QRS related parameters there is a different behavior between males and females. Myocardial Infarction, Arrhythmia, and Congestive Heart Failure are the diseases with greatest impact on the ECG and VCG parameters.
Table 3. Mean values (standard deviation) and 95\% confidence interval of QRS and $\mathrm{T}$ wave amplitudes in males for DM, HYPT, MI and the healthy control group

\begin{tabular}{ccc}
\hline \hline & QRS amplitude & T amplitude \\
\cline { 2 - 3 } Healty & $0.82(0.31)$ & $0.14(0.08)$ \\
& {$[0.78 ; 0.86]$} & {$[0.13 ; 0.15]$} \\
DM & $0.83(0.39)$ & $0.08(0.07)$ \\
& {$[0.76 ; 0.90]$} & {$[0.07 ; 0.10]$} \\
HYPT & $0.90(0.38)$ & $0.11(0.09)$ \\
& {$[0.87 ; 0.93]$} & {$[0.10 ; 0.11]$} \\
MI & $0.76(0.33)$ & $0.08(0.07)$ \\
& {$[0.71 ; 0.82]$} & {$[0.07 ; 0.09]$} \\
\hline \hline
\end{tabular}

Table 4. Mean values (standard deviation) and 95\% confidence interval of QRS and T wave amplitudes in females for DM, HYPT, MI and the healthy control group

\begin{tabular}{ccc}
\hline \hline & QRS amplitude & T amplitude \\
\cline { 2 - 3 } Healty & $0.71(0.26)$ & $0.11(0.08)$ \\
& {$[0.67 ; 0.75]$} & {$[0.10 ; 0.12]$} \\
DM & $0.73(0.31)$ & $0.07(0.06)$ \\
& {$[0.68 ; 0.78]$} & $[0.06 ; 0.08]]$ \\
HYPT & $0.81(0.33)$ & $0.09(0.07)$ \\
& {$[0.78 ; 0.83]$} & {$[0.08 ; 0.09]$} \\
MI & $0.76(0.30)$ & $0.07(0.06)$ \\
& {$[0.69 ; 0.83]$} & {$[0.06 ; 0.09$} \\
\hline \hline
\end{tabular}

Table 5. Comparison of Healty group vs DM, AP, HYPT, MI, ARRH, CHF considering 4 ECG parameters related to QRS wave.

\begin{tabular}{cccccc}
\hline \hline & & $\begin{array}{c}\text { QRS } \\
\text { ampl }\end{array}$ & $\begin{array}{c}\text { QRS } \\
\text { angle }\end{array}$ & $\begin{array}{c}\text { QRS } \\
\text { vector }\end{array}$ & $\begin{array}{c}\text { QRS } \\
\text { area }\end{array}$ \\
\cline { 2 - 6 } DM & m & ns & ns & ns & ns \\
& $\mathrm{f}$ & $\mathrm{ns}$ & $\mathrm{p}<0.01$ & $\mathrm{~ns}$ & $\mathrm{p}<0.01$ \\
\cline { 2 - 6 } AP & $\mathrm{m}$ & $\mathrm{ns}$ & $\mathrm{ns}$ & $\mathrm{ns}$ & $\mathrm{p}<0.01$ \\
& $\mathrm{f}$ & $\mathrm{ns}$ & $\mathrm{ns}$ & $\mathrm{ns}$ & $\mathrm{ns}$ \\
\cline { 2 - 6 } HYPT & $\mathrm{m}$ & $\mathrm{p}<0.01$ & $\mathrm{~ns}$ & $\mathrm{~ns}$ & $\mathrm{p}<0.01$ \\
& $\mathrm{f}$ & $\mathrm{p}<0.01$ & $\mathrm{~ns}$ & $\mathrm{p}<0.01$ & $\mathrm{p}<0.01$ \\
\cline { 2 - 6 } MI & $\mathrm{m}$ & $\mathrm{ns}$ & $\mathrm{ns}$ & $\mathrm{p}<0.01$ & $\mathrm{p}<0.01$ \\
& $\mathrm{f}$ & $\mathrm{ns}$ & $\mathrm{p}=0.02$ & $\mathrm{~ns}$ & $\mathrm{~ns}$ \\
\cline { 2 - 6 } ARRH & $\mathrm{m}$ & $\mathrm{ns}$ & $\mathrm{ns}$ & $\mathrm{ns}$ & $\mathrm{p}<0.01$ \\
& $\mathrm{f}$ & $\mathrm{p}<0.01$ & $\mathrm{p}<0.01$ & $\mathrm{~ns}$ & $\mathrm{p}<0.01$ \\
\cline { 2 - 6 } CHF & $\mathrm{m}$ & $\mathrm{ns}$ & $\mathrm{ns}$ & $\mathrm{ns}$ & $\mathrm{ns}$ \\
& $\mathrm{f}$ & $\mathrm{p}<0.01$ & $\mathrm{p}<0.01$ & $\mathrm{~ns}$ & $\mathrm{p}<0.01$ \\
\hline \hline
\end{tabular}


Table 6. Comparison of Healty group vs DM, AP, HYPT, MI, ARRH, CHF considering 4 ECG parameters related to QRS-T wave.

\begin{tabular}{cccccc}
\hline \hline & & QRS & \multicolumn{1}{c}{$\begin{array}{c}\text { ST } \\
\text { elevatl }\end{array}$} & $\begin{array}{c}\text { QRS/T } \\
\text { angle }\end{array}$ & T ampl \\
\cline { 2 - 6 } DM & round & ns & $n s$ & $n s$ & $\mathrm{p}<0.01$ \\
& $\mathrm{f}$ & $\mathrm{ns}$ & $\mathrm{ns}$ & $\mathrm{ns}$ & $\mathrm{p}<0.01$ \\
\cline { 2 - 6 } AP & $\mathrm{m}$ & $\mathrm{p}<0.01$ & $\mathrm{~ns}$ & $\mathrm{~ns}$ & $\mathrm{p}<0.01$ \\
& $\mathrm{f}$ & $\mathrm{ns}$ & $\mathrm{ns}$ & $\mathrm{ns}$ & $\mathrm{p}<0.01$ \\
\cline { 2 - 6 } HYPT & $\mathrm{m}$ & $\mathrm{p}<0.01$ & $\mathrm{~ns}$ & $\mathrm{~ns}$ & $\mathrm{p}<0.01$ \\
& $\mathrm{f}$ & $\mathrm{ns}$ & $\mathrm{ns}$ & $\mathrm{ns}$ & $\mathrm{p}<0.01$ \\
\cline { 2 - 6 } MI & $\mathrm{m}$ & $\mathrm{p}<0.01$ & $\mathrm{~ns}$ & $\mathrm{~ns}$ & $\mathrm{p}<0.01$ \\
& $\mathrm{f}$ & $\mathrm{ns}$ & $\mathrm{ns}$ & $\mathrm{ns}$ & $\mathrm{p}<0.01$ \\
\cline { 2 - 6 } ARRH & $\mathrm{m}$ & $\mathrm{p}<0.01$ & $\mathrm{~ns}$ & $\mathrm{~ns}$ & $\mathrm{p}<0.01$ \\
& $\mathrm{f}$ & $\mathrm{ns}$ & $\mathrm{ns}$ & $\mathrm{p}<0.01$ & $\mathrm{p}<0.01$ \\
\cline { 2 - 6 } CHF & $\mathrm{m}$ & $\mathrm{p}<0.01$ & $\mathrm{~ns}$ & $\mathrm{~ns}$ & $\mathrm{p}<0.01$ \\
& $\mathrm{f}$ & $\mathrm{ns}$ & $\mathrm{ns}$ & $\mathrm{p}<0.01$ & $\mathrm{p}<0.01$ \\
\hline \hline
\end{tabular}

\section{Aknowledgements}

The authors acknowledge the Italian Longitudinal Study on Aging project of CNR, and the ILSA Working Group: L Amaducci, G Scarlato, M Baldereschi, L Candelise, A Di Carlo, F Grigoletto, S Maggi, N Minicuci, M Noale, E Scarpini, G Volonnino, G Bortolan, M Bressan, C Loeb, C Gandolfo, N Canal, M Franceschi, L Battistin, G Enzi, A Ghetti, D Inzitari, R Vergassola, S Bonaiuto, F Rengo, A Capurso, P Livrea, L Motta.

\section{References}

[1] Nakamura S, Uzu T, Inenaga T, Kimura G. Prediction of coronary artery disease and cardiac events using electrocardiographic changes during hemodialysis. Am J Kidney Dis. 2000;36(3):592-9.

[2] Simova I, Christov I, Bortolan G, Abächerli R, Kambova L. Jekova I. Hemodialysis induced ST-segment deviation. Comp. Card. 2015;42:1133-6.

[3] Iuliano S, Fisher S,Karasik P, et al. QRS duration and mortality in patients with congestive heart failure. Am Heart J. 2002;143(6):1085-91.

[4] Kashani A, Barold S. Significance of QRS complex duration in patients with heart failure. J Am Coll Cardiol. 2005;46(12):2183-92.

[5] DeBruyne MC, Hoes AW, Kors JA, et al. QTe dispersion predicts cardiac mortality in the elderly: the Rotterdam Study. Circulation 1998;97(5):467-472.

[6] Sheehan J, Perry IJ, Reilly M, et al. QT dispersion, QT maximum and risk of cardiac death in the Caerphilly Heart Study. Eur J Cardiovasc Prev Rehabil. 2004;11(1):63-8.

[7] Simova I, Bortolan G, Christov I. ECG attenuation phenomenon with advancing age. J Electrocard. 2018;51(6):1029-34.
Table 7. Comparison of Healty group vs DM, AP, HYPT, MI, ARRH, CHF considering 4 ECG parameters related to T wave.

\begin{tabular}{|c|c|c|c|c|c|}
\hline & & $\frac{\mathrm{T}}{\text { ratio }}$ & $\begin{array}{c}\mathrm{T} \\
\mathrm{PCA}\end{array}$ & $\begin{array}{c}\mathrm{T} \\
\text { round }\end{array}$ & TWAD \\
\hline DM & $\begin{array}{c}\mathrm{m} \\
\mathrm{f}\end{array}$ & $\begin{array}{l}p<0.01 \\
p<0.01\end{array}$ & $\begin{array}{l}p<0.01 \\
p<0.01\end{array}$ & $\begin{array}{l}\mathrm{p}<0.01 \\
\mathrm{p}<0.01\end{array}$ & $\begin{array}{l}\mathrm{p}<0.01 \\
\mathrm{p}<0.01\end{array}$ \\
\hline AP & $\begin{array}{c}\mathrm{m} \\
\mathrm{f}\end{array}$ & $\begin{array}{c}\mathrm{p}<0.01 \\
\mathrm{p}=0.012\end{array}$ & $\begin{array}{l}\mathrm{p}<0.01 \\
\mathrm{p}<0.01\end{array}$ & $\begin{array}{l}\mathrm{p}<0.01 \\
\mathrm{p}<0.01\end{array}$ & $\begin{array}{l}\mathrm{p}<0.01 \\
\mathrm{p}<0.01\end{array}$ \\
\hline HYPT & $\begin{array}{c}\mathrm{m} \\
\mathrm{f}\end{array}$ & $\begin{array}{l}p<0.01 \\
p<0.01\end{array}$ & $\begin{array}{l}p<0.01 \\
p<0.01\end{array}$ & $\begin{array}{l}p<0.01 \\
p<0.01\end{array}$ & $\begin{array}{l}\mathrm{p}<0.01 \\
\mathrm{p}<0.01\end{array}$ \\
\hline MI & $\underset{f}{m}$ & $\begin{array}{l}\mathrm{p}<0.01 \\
\mathrm{p}<0.01\end{array}$ & $\begin{array}{l}\mathrm{p}<0.01 \\
\mathrm{p}<0.01\end{array}$ & $\begin{array}{l}\mathrm{p}<0.01 \\
\mathrm{p}<0.01\end{array}$ & $\begin{array}{l}\mathrm{p}<0.01 \\
\mathrm{p}<0.01\end{array}$ \\
\hline ARRH & $\begin{array}{c}\mathrm{m} \\
\mathrm{f}\end{array}$ & $\begin{array}{l}p<0.01 \\
p<0.01\end{array}$ & $\begin{array}{l}p<0.01 \\
p<0.01\end{array}$ & $\begin{array}{l}\mathrm{p}<0.01 \\
\mathrm{p}<0.01\end{array}$ & $\begin{array}{l}\mathrm{p}<0.01 \\
\mathrm{p}<0.01\end{array}$ \\
\hline $\mathrm{CHF}$ & $\begin{array}{c}\mathrm{m} \\
\mathrm{f}\end{array}$ & $\begin{array}{l}\mathrm{p}<0.01 \\
\mathrm{p}<0.01\end{array}$ & $\begin{array}{l}\mathrm{p}<0.01 \\
\mathrm{p}<0.01\end{array}$ & $\begin{array}{l}\mathrm{p}<0.01 \\
\mathrm{p}<0.01\end{array}$ & $\begin{array}{l}\mathrm{p}<0.01 \\
\mathrm{p}<0.01\end{array}$ \\
\hline
\end{tabular}

[8] Jones J, Srodulski ZM, Romisher S. The aging electrocardiogram. Am J Emerg Med 1990;8(3):240-5. https://doi.org/10.1016/0735-6757(90)90331-S.

[9] Maggi S, Zucchetto M, Grigoletto F, Baldereschi M, Candelise L, Scarpini E, ... ILSA Group. The Italian longitudinal study on aging (ILSA): design and methods. Aging Clin Exper Res. 1994:6(6);464-73.

[10] Bortolan G, Bressan M, Golferini F, ILSA Study Group. QT dispersion in the elderly. The ILSA study. Aging Clin Exp Res 2004;16(5):342-8.

[11] Levkov C, Mihov G, Ivanov R, Daskalov I, Christov I, Dotsinsky I. Removal of power-line interference from the ECG: a review of the subtraction procedure. Biom Eng Online, 2005:4(1), 50. doi: 10.1186/1475-925X-4-50

[12] Bortolan G, Christov I, Simova I, Dotsinsky I. Noise processing in exercise ECG stress test for the analysis and the clinical characterization of QRS and T wave alternans. Biomed Sign Process Contr. 2015;18:378-85.

[13] Christov I, Neycheva T, Schmid R, Stoyanov T, Abächerli R. Pseudo real-time low-pass filter in ECG, self-adjustable to the frequency spectra of the waves. Med Biol Eng Comp. 2017;55(9):1579-88

[14] Kenttä TV, Sinner MF, ..., Huikuri HV. Repolarization heterogeneity measured with Twave area dispersion in Standard 12-lead ECG predicts sudden cardiac death in general population. Circ Arrhytm Electrophys. 2018;11:1-11

[15] Dower GE. A lead synthesizer for the Frank system to simulate the standard 12-lead electrocardiogram. J Electrocard. 1968;1(1);101-6.

[16] Sedaghat G, Ghafoori E, Waks JW, Kabir MM, Shvilkin A, Josephson ME, Tereshchenko LG Quantitative assessment of vectorcardiographic loop morphology. J Electrocardiol. 2016;49(2):154-63.

Address for correspondence.

Giovanni Bortolan , IN-CNR

Corso Stati Uniti 4, 35129 - Padova, Italy

e-mail: giovanni.bortolan@cnr.it 